\title{
Article \\ Vitamin E Deficiency Disrupts Gene Expression Networks during Zebrafish Development
}

\author{
Brian Head ${ }^{1,2}\left(\right.$, Stephen A. Ramsey ${ }^{3,4}$, Chrissa Kioussi ${ }^{5}\left(\right.$, , Robyn L. Tanguay ${ }^{6}(\mathbb{C}$ and Maret G. Traber $1,7, *(1)$ \\ 1 Linus Pauling Institute, Oregon State University, Corvallis, OR 97331, USA; brian.head@oregonstate.edu \\ Molecular and Cellular Biology Program, Oregon State University, Corvallis, OR 97331, USA \\ 3 Department of Biomedical Sciences, College of Veterinary Medicine, Oregon State University, Corvallis, \\ OR 97331, USA; stephen.ramsey@oregonstate.edu \\ 4 School of Electrical Engineering and Computer Science, Oregon State University, Corvallis, OR 97331, USA \\ 5 Department of Pharmaceutical Sciences, College of Pharmacy, Oregon State University, Corvallis, OR 97331, \\ USA; chrissa.kioussi@oregonstate.edu \\ 6 Department of Environmental Toxicology, College of Agricultural Sciences, Oregon State University, \\ Corvallis, OR 97331, USA; Robyn.Tanguay@oregonstate.edu \\ 7 School of Biological and Population Health Sciences, College of Public Health, Oregon State University, \\ Corvallis, OR 97331, USA \\ * Correspondence: maret.traber@oregonstate.edu
}

\section{check for}

updates

Citation: Head, B.; Ramsey, S.A. Kioussi, C.; Tanguay, R.L.; Traber, M.G. Vitamin E Deficiency Disrupts Gene Expression Networks during Zebrafish Development. Nutrients 2021, 13, 468. https://doi.org/ $10.3390 /$ nu13020468

Received: 23 December 2020

Accepted: 27 January 2021

Published: 30 January 2021

Publisher's Note: MDPI stays neutral with regard to jurisdictional claims in published maps and institutional affiliations.

Copyright: (c) 2021 by the authors. Licensee MDPI, Basel, Switzerland. This article is an open access article distributed under the terms and conditions of the Creative Commons Attribution (CC BY) license (https:/ / creativecommons.org/licenses/by/ $4.0 /)$.

\begin{abstract}
Vitamin E (VitE) is essential for vertebrate embryogenesis, but the mechanisms involved remain unknown. To study embryonic development, we fed zebrafish adults ( $>55$ days) either VitE sufficient $(\mathrm{E}+$ ) or deficient $(\mathrm{E}-$ ) diets for $>80$ days, then the fish were spawned to generate $\mathrm{E}+$ and $\mathrm{E}-$ embryos. To evaluate the transcriptional basis of the metabolic and phenotypic outcomes, E+ and E- embryos at 12, 18 and $24 \mathrm{~h}$ post-fertilization (hpf) were subjected to gene expression profiling by RNASeq. Hierarchical clustering, over-representation analyses and gene set enrichment analyses were performed with differentially expressed genes. E- embryos experienced overall disruption to gene expression associated with gene transcription, carbohydrate and energy metabolism, intracellular signaling and the formation of embryonic structures. mTOR was apparently a major controller of these changes. Thus, embryonic VitE deficiency results in genetic and transcriptional dysregulation as early as $12 \mathrm{hpf}$, leading to metabolic dysfunction and ultimately lethal outcomes.
\end{abstract}

Keywords: VitE; vitamin E; E+, VitE sufficient; E-, VitE deficient; hpf; hours post-fertilization; $\alpha$-TTP; $\alpha$-tocopherol transfer protein.

\section{Introduction}

Vitamin E (VitE) is a potent lipophilic antioxidant and is localized in membranes to protect against lipid peroxidative damage [1]. VitE contributes to membrane fluidity via protection of oxidizable lipid and stabilizes membrane domains to assist cell signaling cascades dependent on membrane protein-protein interactions and ion permeability [2]. VitE must be provided in the diet because it is produced only by photosynthetic organisms, where it accumulates in plant seeds and early embryonic structures [3]. Although VitE was discovered as a dietary component necessary to prevent fetal resorption in rats [4], the molecular basis for this requirement still remains under investigation.

The vertebrate embryonic VitE requirement is time-dependent and is needed between embryonic days (E) 9.5 and 11.5 in rats [5], a developmentally similar period to that of zebrafish between 12 and $24 \mathrm{~h}$ post-fertilization (hpf) [6,7]. During this window, the zebrafish embryo undergoes significant growth, nearly tripling in length [8]. This period coincides with segmentation of the mesoderm into somites, notochord vacuolation, and primary and secondary neurulation resulting in brain regionalization and neural tube expansion. We showed both by (1) using morpholinos to block the embryonic translation of the mRNA for the $\alpha$-tocopherol transfer protein ( $\alpha$-TTP) [9] and by (2) evaluating neuronal 
structures in VitE-deficient embryos (E-) [10-12] that VitE is essential during the early stages of zebrafish neurogenesis. Specifically, blocking TTP mRNA translation with an oligonucleotide in zebrafish was $100 \%$ lethal by $24 \mathrm{hpf}$ with noticeable impairment of brain and eye development beginning at $12 \mathrm{hpf}$ [9]. VitE deficiency caused by defective lipoprotein metabolism also produces neurodevelopmental defects in mice, including neural tube defects [13] and exencephaly [14]. Additional neurologic impairments have been reported in Ttpa ${ }^{-/}$mice, which show degeneration of cerebellar Purkinje [15] and spinal cord neurons [16].

In addition to morphologic derangements, E- zebrafish embryos also experience lethal dysregulation of glycolytic metabolism in the first $120 \mathrm{hpf}$ [11], which could be remedied by glucose supplementation at $24 \mathrm{hpf}$. Notably, E- embryos experience a hypermetabolic state at $24 \mathrm{hpf}$, which switches to a hypometabolic state by $48 \mathrm{hpf}$. Importantly, carbohydrate metabolism is necessary to provide precursor molecules for the rapid growth of zebrafish embryos especially between 0 and $48 \mathrm{hpf}$ [17]. In addition, E- embryos between 24 and $48 \mathrm{hpf}$ experience errors in amino acid metabolism and generation of precursor ribonucleotides, tricarboxylic acid (TCA) cycle intermediates and demonstrate over-production of free saturated fatty acids $[11,18]$. E- embryos by $12 \mathrm{hpf}$ experience increased betaine concentrations, suggesting that this methyl donor is needed for the methionine cycle to maintain S-adenosyl methionine production [19]. These data suggest that epigenetic regulation may be impacted by VitE deficiency. Lee et al. showed that blocking folic acid metabolism and thus preventing methyl donor recycling causes also neurologic defects in zebrafish embryos as early as $10 \mathrm{hpf}$ [20].

Zebrafish development is coordinated by temporal and spatial gene expression networks. Transcriptional regulation is a key component of embryonic fate [21]. The mechanistic target of the rapamycin (mTOR) complex senses energy status, amino acid abundance and redox imbalance to regulate cell survival and proliferation [22,23]. Additionally, in zebrafish, mTOR signaling is necessary in myelination pathways throughout development of the central and peripheral nervous system [24]. VitE deficiency may disrupt metabolic pathways regulated by and restored by mTOR signal integration. Metabolic dysfunction is likely the cause and consequence of transcriptional network alterations that regulate metabolic needs for rapid growth and development [25]. Thus, the VitE deficient state may have marked effects on temporal gene expression patterns in the zebrafish embryo specifically during neural tube formation and brain development. The objective of this study was to identify transcriptional targets of VitE deficiency in embryo development longitudinally. Due to early disruption of the metabolic state in E- embryos [11,18], we examined changes prior to $24 \mathrm{hpf}$. We hypothesize that VitE is necessary to protect zebrafish transcriptional networks associated with metabolism, cell signaling and embryo energy status. In addition, we sought to identify transcription factors necessary for zebrafish embryo nervous system development that are VitE-dependent and produce the morphological defects previously observed [12,19].

\section{Methods}

\subsection{Zebrafish Husbandry}

All experimental protocols and methods were carried out in accordance with the animal use and care protocol (\# 5068) approved by the Institutional Animal Care and Use Committee at Oregon State University. Tropical 5D strain zebrafish were reared in the Sinnhuber Aquatic Research Laboratory at Oregon State University under standard laboratory conditions of $28^{\circ} \mathrm{C}$ on a $14 \mathrm{~h}$ light $/ 10 \mathrm{~h}$ dark photoperiod according to standard zebrafish breeding protocols [8]. At 55 days post-fertilization (dpf), adult zebrafish were randomly allocated to two experimental diets, vitamin E deficient (E-) or sufficient (E+), as described [10].

VitE was extracted from the diets prior to feeding and assayed by HPLC-UV prior to feeding, as described [26]. In the E+ diet, $\alpha$ - and $\gamma$-tocopherols were $361 \pm 10$ and $2.6 \pm 0.0 \mathrm{mg} / \mathrm{kg} \pm \operatorname{SEM}(n=3$ measurements), respectively. In the E- diet, $\alpha$ - and $\gamma$ - 
tocopherols were $1.1 \pm 0.0$ and $0.5 \pm 0.0 \mathrm{mg} / \mathrm{kg}$ ( $n=3$ measurements), respectively. Eand E+ embryos were obtained by group spawning of adult fish fed either E- or E+ diets for a minimum of 80 days up to 9 months. Embryos were collected, staged and incubated until use in standard embryo media $(15 \mathrm{mM} \mathrm{NaCl}, 0.5 \mathrm{mM} \mathrm{KCl}, 1 \mathrm{mM} \mathrm{MgSO}, 0.15 \mathrm{mM}$ $\mathrm{KH}_{2} \mathrm{PO}_{4}, 0.05 \mathrm{mM} \mathrm{Na}_{2} \mathrm{HPO}_{4}, 1 \mathrm{mM} \mathrm{CaCl}, \mathrm{NaHCO}_{3}$ in fish system water, (EM)). Embryos at each time point $(12,18,24 \mathrm{hpf})$ were staged according to the appropriate developmental landmarks [8]; embryos at $12 \mathrm{hpf}$ with the presence of 6 somites, $18 \mathrm{hpf}$ with the presence of 18 somites and defined otic vesicle, and at $24 \mathrm{hpf}$ (prim-5 stage) upon first pigment formation in the retinal epithelium and presence of 30 somites. To evaluate transcriptional differences based solely on VitE status, only embryos identified as morphologically normal and at the appropriate developmental landmarks were used for analysis. Embryos were euthanized with tricaine (MS222, ethyl 3-aminobenzoate methanesulfonate salt, Sigma Aldrich) in accordance to animal care and use guidelines.

\subsection{RNA Extraction and Sequencing}

RNA was extracted from embryos staged developmentally at 12, 18 and $24 \mathrm{hpf}$, pooled ( $n=10$ embryos/sample) and homogenized, with 4 sample pools per VitE status. RNA integrity $(9.02 \pm 0.15, n=24)$ was assessed using the 2100 BioAnalyzer Instrument (Agilent) at the Center for Genome Research and Biocomputing at Oregon State University (Supplementary Materials). RNA libraries were prepared with the Lexogen QuantSeq 3' mRNA Seq Library Prep Kit-FWD kits (Lexogen, Vienna, Austria). After library preparation, samples were pooled and sequenced using single-end sequencing with $100 \mathrm{bp}$ reads on an Illumina HiSeq3000 instrument (Illumina, San Diego, CA, USA).

\subsection{Data Deposition}

RNASeq data for this study has been deposited in Gene Expression Omnibus with accession number GSE164848 and can be viewed at: https:/ / www.ncbi.nlm.nih.gov/geo/ query / acc.cgi?acc=GSE164848.

\subsection{Data Processing and Statistical Analysis}

Data processing was performed using the default parameters provided by the program manuals unless stated otherwise. Sequence read quality was first assessed using FastQC v0.11.5. Adapters and poly(A) tails were trimmed using bbduk v35.92. Trimmed reads were then aligned to the current reference genome (GRCz11, D. rerio) with current annotations (Ensemb1 100) using STAR aligner, v2.7.3a. Raw gene counts were summarized with edgeR, Bioconductor v3.24.3 in R, v4.0.2. Data were normalized by the TMMwsp (Trimmed Mean of $\mathrm{M}$-values with singleton pairing) method.

Multidimensional scaling plots (MDS) were computed to assess the similarity of group effects, identified as the interaction of diet and time, and the sequencing lane effects between samples. edgeR generalized linear model ( $\mathrm{glm}$ ) was used to fit the data and estimate the common, trended and tagwise dispersions given the experimental design. A quasi-likelihood F-test (QLF) was used to compute differential gene expression between E+ and E- embryo gene expression at each time point measured ( $n=3$ time points; 12,18 , $24 \mathrm{hpf}$ ). Heatmaps were generated using z-score transformed counts per million (CPM) of differentially expressed (DE) genes identified by adjusted $p$-value, or Benjamini-Hochberg False Discovery Rate (FDR) $<0.1$.

\subsection{Gene Ontology and Network Enrichment}

DE genes were subject to Gene Ontology (GO) enrichment analysis using the Bioconductor R package GOseq, v.1.40.0. Over representation analysis (ORA) was performed with $\mathrm{DE}$ genes and DE genes with absolute value $\log _{2} \mathrm{FC} \geq 1$ found at all time points using WebGestalt [27]. Gene set enrichment (GSEA) was performed with pre-ranked genes computed with $\log _{2} \mathrm{FC}$ and $p$-value using WebGestalt. Differentially expressed transcription factors (TFs) were identified and described by predicted anatomical regions using ZFIN [28]. 
All network enrichment was considered significant if $F D R<0.25$. Metabolomic data from $24 \mathrm{hpf}$ embryos previously acquired [11] were integrated with $24 \mathrm{hpf}$ transcriptomic profiles using MetaboAnalyst [29].

\subsection{Western Blotting}

Protein was extracted from pooled $(n=30) \mathrm{E}+$ and E- embryos at $24 \mathrm{hpf}$ in RIPA buffer supplemented with protease and protein phosphatase inhibitors (Calbiochem, La Jolla, CA, USA). Rat liver extract was used as a positive control for the assay. Extracted protein $(25 \mu \mathrm{g})$ was subjected to SDS-Page and processed by immunoblotting. All gels and blots were run simultaneously. The proteins were visualized by SuperSignal ${ }^{\mathrm{TM}}$ West Pico Chemiluminescent Substrate (ThermoFisher, Carlsbad, CA, USA) and quantified using the Bio-Rad Image System (Hercules, CA, USA). The information for antibodies is listed in the supplementary information. Phospho-protein ( $\mathrm{p}-$ ) to unphosphorylated protein ratio is calculated for the representative lanes shown.

\section{Results}

Morphological deformities including yolk sac and pericardial edemas, bent axes, and apparent developmental delays generally occur after $24 \mathrm{hpf}$ in E- embryos as previously reported [12]. To evaluate gene expression differences based on VitE status alone and not phenotypic changes, only embryos identified as morphologically normal were used. All appropriate developmental landmarks were used for the following analyses. Thus, the transcriptional profiles reported herein are powerful determinants of the underlying effects of VitE deficiency because they are not changes induced by physical deformities that induce further stress on the animal.

\subsection{Hierarchical Clustering and Gene Annotation}

To determine the VitE-dependent effects on global transcriptomic changes during embryo development, RNA was isolated from $\mathrm{E}+$ and $\mathrm{E}-$ whole embryo lysates $(n=4$ pools, 10 embryos/pool) at the three time points, 12, 18 and 24 hpf. Multidimensional scaling analysis indicated strong separation between the gene expression profiles by time point and further by embryo VitE status (Supplementary Figure S1). Sequencing lane effects were similarly analyzed but with little to no effect on gene expression profiles, thus are disregarded from further analysis. Of the 22,796 sequenced genes, 2355 were identified as different $(p<0.05)$ across all time points and by VitE status. From this selected group of genes, $12 \%$ $(n=285)$ were considered differentially expressed (DE) under a false discovery rate threshold $(F D R<0.1)$. A heatmap of DE genes was clustered with $z$-score averages according to VitE status, age and gene (Figure 1). Gene clusters from the heatmap were annotated for gene ontology (GO) terms associated with biological processes (BP), molecular function (MF) and cellular component (CC). Cluster 1, identifiable by reduced gene expression in $\mathrm{E}$ - embryos at $12 \mathrm{hpf}$, was significantly $(F D R<0.25)$ associated with organic acid binding (GO:0043177), iron ion binding (GO:0005506), and carbohydrate binding (GO:0030246). Vitamin binding ( $F D R=0.06$, GO:0019842) refers to genes associated with L-ascorbic acid binding capacity, including egln2, $p 4 h a 1 b$, and plod1a. Cluster 2 was significantly associated with peptidase activity (GO:0008233) and unfolded protein binding (GO:0051082). Cluster 3, identifiable by increased gene expression in E+ embryos at 12 and $18 \mathrm{hpf}$, was significantly associated with protein-containing complex binding (GO:0044877), cell adhesion molecule binding (GO:0050839) and cytoskeletal protein binding (GO:0008092). Cluster 4 genes were defined by GO terms vacuole (GO:0005773) and extracellular region part (GO:0044421). The term "vacuole" was associated with endolysosomal trafficking-associated genes $a b c c 6 a$, galca, and zgc:110239. 


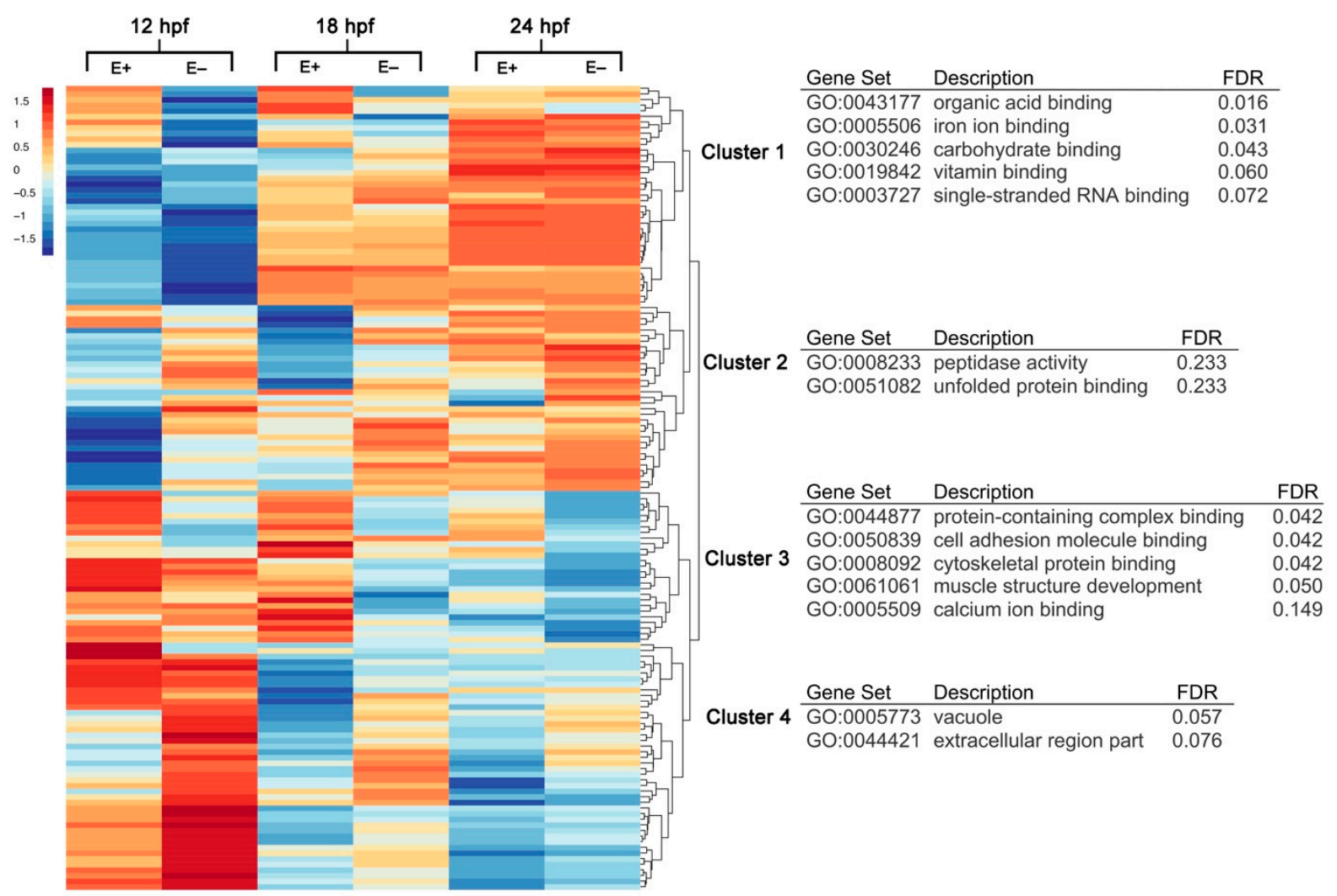

Figure 1. Hierarchical clustering and gene annotation of differentially expressed genes in E- and E+ embryos at 12,18 and $24 \mathrm{hpf}$. Heatmap of all differentially expressed (DE) genes $(n=286, F D R<0.1)$ clustered with $z$-score averages according to VitE status, age and gene with red color indicating greater expression relative to all-condition average and blue color indicating lower expression relative to all-condition average amongst all expression values (rows correspond to genes, columns correspond to conditions). Clusters within heatmap annotated by Gene Ontology (GO) terms organized by Benjamini-Hochberg False Discovery Rate (FDR).

Overall, in E- relative to E+ embryos, there were $110 \mathrm{DE}$ genes with increased expression levels (Figure 2A) and $80 \mathrm{DE}$ genes with decreased expression levels (Figure 2B). DE genes that were observed consistently with increased expression in E- embryos were associated significantly with the following KEGG (Kyoto Encyclopedia of Genes and Genomes) pathways-glycolysis/gluconeogenesis, carbon metabolism, biosynthesis of amino acids, pentose phosphate pathway and fructose and mannose pathways $(F D R<0.25$, Figure 2C). DE genes that were observed consistently with decreased expression in E- embryos were associated significantly with pyrimidine metabolism and proteasome pathways (Figure 2D).

\subsection{Top Differentially Expressed Genes in E- Embryos}

The top 10 DE genes (e.g., with the largest log-fold changes) with increased or decreased expression levels in E- embryos relative to E+ embryos were identified at each of the three time points $(12,18$ or $24 \mathrm{hpf}$; Table 1$)$. DE genes that increased at all three time points in E- embryos include olfce2 (olfactory receptor C family, e2), which is predicted to be involved in $\mathrm{G}$ protein-coupled receptor signaling, and cngb3.2 (cyclic nucleotide gated channel subunit beta 3, tandem duplicate 2), which is predicted to have cGMP binding activity and is involved in cation transmembrane transport. DE genes that decreased at all three time points in E- embryos include serpina7 (serpin peptidase inhibitor, clade A, member 7), a serine-type endopeptidase inhibitor implicated in mTOR-related neuropathology in zebrafish [30] and numerous unnamed genes si:dkey-73p2.2, si:dkey-15j16.6, and si:dkey-23k10.3. nitr3r.1l (novel immune-type receptor 3, related 1-like) was found initially (12 and $18 \mathrm{hpf}$ ) to be increased highly in E- embryos, but was decreased highly at $24 \mathrm{hpf}$. 
A

Up in E-vs. E+

$12 \mathrm{hpf}$

$18 \mathrm{hpf}$

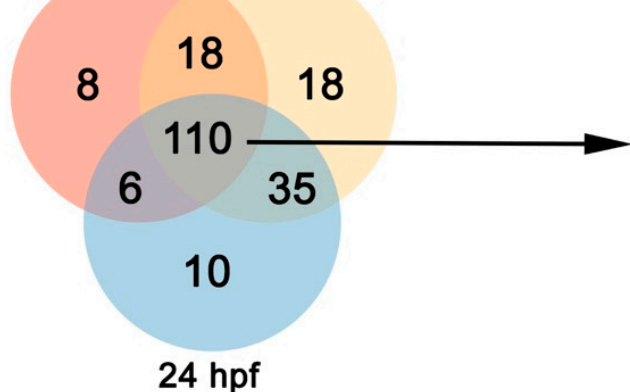

B

Down in E- vs. E+

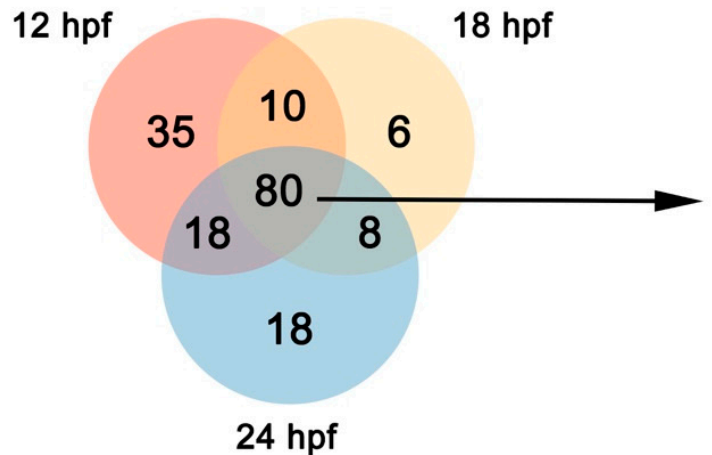

C

Up in E- KEGG enrichment

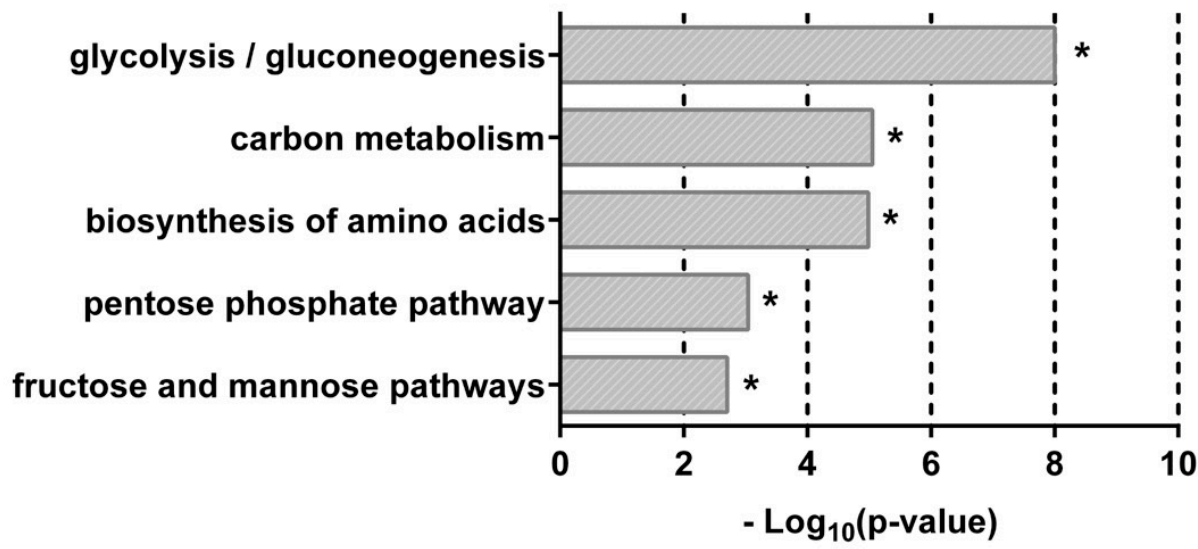

Down in E- KEGG enrichment

protein processing in endoplasmic reticulum pyrimidine metabolism

proteasome

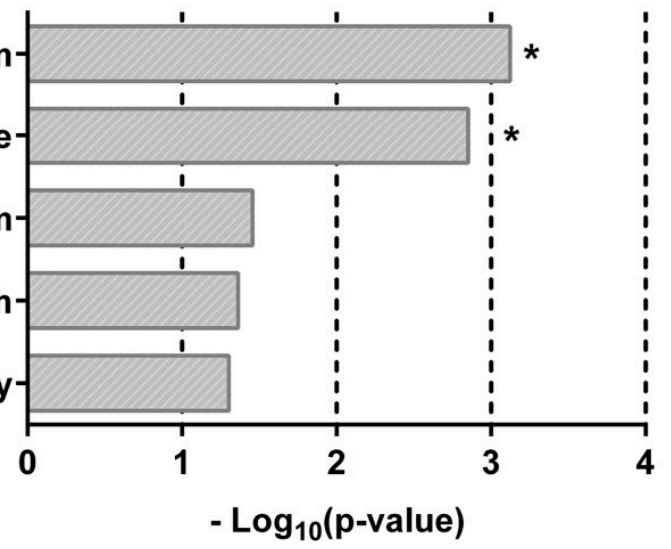

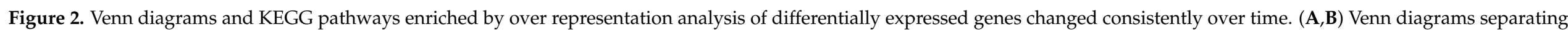

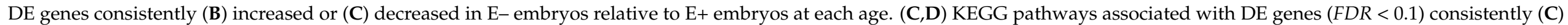
increased or decreased (D) in E- embryos vs. E+ embryos at each time point (12, 18, and 24 hpf). * indicates significant $F D R<0.25$. 


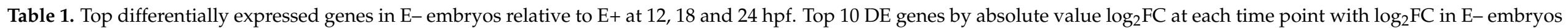
relative to E+. $\uparrow$ and $\downarrow$ indicate a DE gene found in the top 10 consistently increased or decreased in E- embryos at each age (12, 18, 24 hpf).

\begin{tabular}{|c|c|c|c|c|c|}
\hline \multicolumn{2}{|c|}{$12 \mathrm{hpf}$} & \multicolumn{2}{|c|}{$18 \mathrm{hpf}$} & \multicolumn{2}{|c|}{$24 \mathrm{hpf}$} \\
\hline Gene Symbol & $\log _{2} \mathrm{FC}$ in $\mathrm{E}-$ & Gene Symbol & $\log _{2} \mathrm{FC}$ in $\mathrm{E}-$ & Gene Symbol & $\log _{2} F C$ in $\mathrm{E}-$ \\
\hline 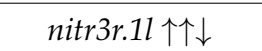 & 6.129 & cngb3.2 $\uparrow \uparrow$ & 2.944 & olfce $2 \uparrow \uparrow \uparrow$ & 5.822 \\
\hline si:dkey-90m5.4 & 3.135 & olfce $2 \uparrow \uparrow \uparrow$ & 2.472 & si:dkey-23k10.3 $\downarrow \uparrow$ & 4.389 \\
\hline tnnc1a & 3.048 & ighd $\uparrow \uparrow$ & 2.326 & 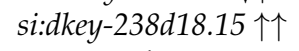 & 3.404 \\
\hline olfce $2 \uparrow \uparrow \uparrow$ & 3.023 & апрера $\uparrow \uparrow$ & 2.129 & polr3c & 2.768 \\
\hline cd40lg & 2.924 & 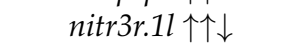 & 2.068 & topaz1 & 2.242 \\
\hline slc $25 a 55 b$ & 2.496 & 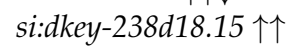 & 2.003 & aпpepa $\uparrow \uparrow$ & 1.815 \\
\hline ribc1 & 2.386 & rnps 1 & 1.801 & si:dkey-238d18.5 & 1.813 \\
\hline si:dkey-159f12.2 & 2.225 & sn $\times 21$ & 1.662 & $d n t t$ & 1.516 \\
\hline$s c d b$ & 2.145 & si:dkey-90m5.4 & 1.635 & $f 2 r l 1.2$ & 1.505 \\
\hline b3gat2 & -4.178 & serpina7 $\downarrow \downarrow \downarrow$ & -4.396 & 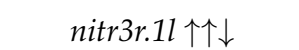 & -2.692 \\
\hline serpina7 $\downarrow \downarrow \downarrow$ & -2.993 & si:dkey-15j16.6 $\downarrow \downarrow$ & -2.998 & si:ch211-191i18.2 & -2.657 \\
\hline loxhd1b $\downarrow \downarrow$ & -2.787 & si:dkey-73p2.2 $\downarrow \downarrow \downarrow$ & -2.901 & si:dkey-15j16.6 $\downarrow \downarrow$ & -2.648 \\
\hline si:dkey-73p2.2 $\downarrow \downarrow \downarrow$ & -2.673 & $z g c: 158445$ & -2.839 & serpina7 $\downarrow \downarrow \downarrow$ & -2.629 \\
\hline asb13a.1 & -2.666 & si:ch1073-13h15.3 & -2.680 & si:dkey-73p2.2 $\downarrow \downarrow \downarrow$ & -2.231 \\
\hline rfesd & -2.532 & si:dkey-23k10.3 $\downarrow \uparrow$ & -2.460 & $z g c: 173585$ & -1.617 \\
\hline$n r 2 f 1 b$ & -2.205 & grin1b & -1.573 & $z g c: 101562$ & -1.453 \\
\hline proca & -2.069 & kiaa1549lb & -1.570 & insl5a & -1.206 \\
\hline si:ch1073-268j14.1 & -2.041 & ormdl3 & -1.417 & dock11 & -1.125 \\
\hline
\end{tabular}


To evaluate the gene product properties of highly DE genes identified, over-representation analysis was performed using DE genes with absolute value $\log _{2} \mathrm{FC} \geq 1$, or 2-fold differences between $\mathrm{E}$ - and $\mathrm{E}+$ gene expression values. Top $\mathrm{GO}$ terms $(F D R<0.05)$ are shown in ascending $p$-value order (Figure 3). DE genes in E- embryos annotated for Biological Process (BP) indicated highly related metabolic processes, including the generation of precursor metabolites and energy and carbohydrate metabolic processes (Figure 3A). The Molecular Function (MF) domain annotations included oxidoreductase activity, glutamate and peptide receptor activity and binding related to cell cycle progression (Figure 3B). Annotations associated with Cellular Component (CC) included further description of energy generation by the respiratory chain complex and other membrane protein complexes (Figure 3C).

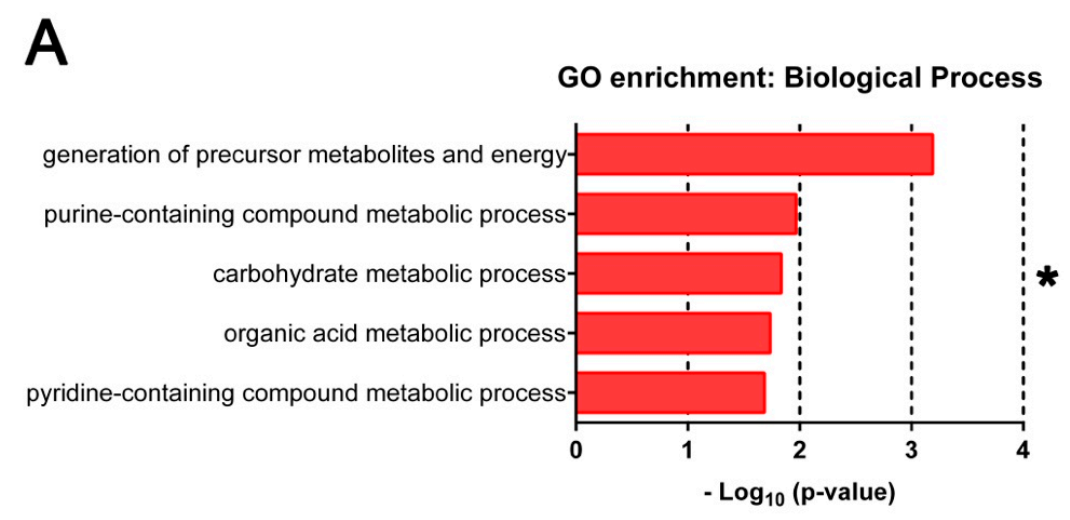

B

GO enrichment: Molecular Function
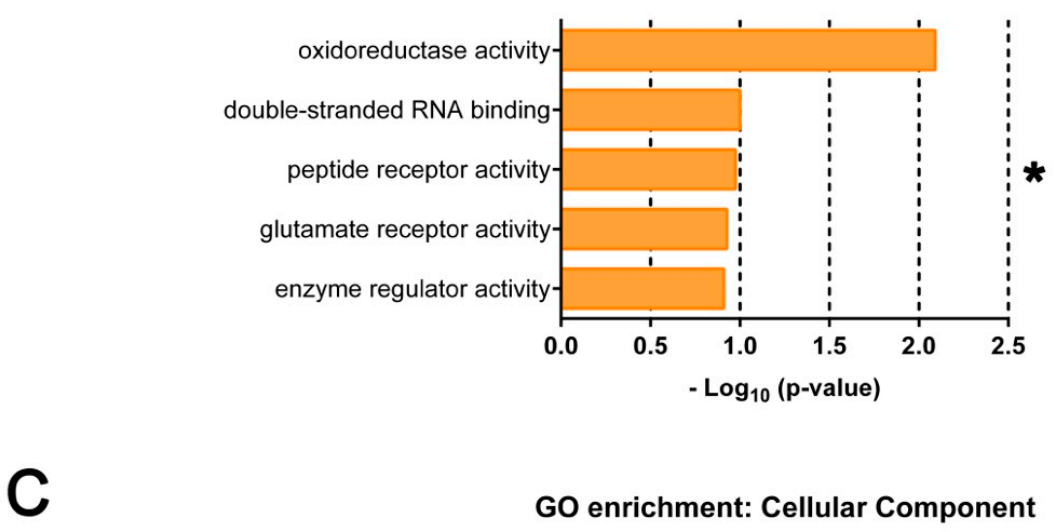

GO enrichment: Cellular Component

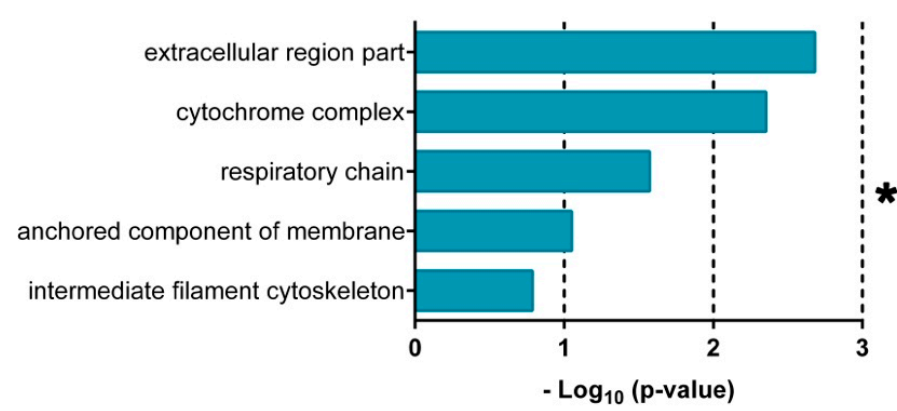

Figure 3. Gene ontology terms enriched by over representation analysis and gene set enrichment analysis of all differentially expressed genes. GO annotations associated with most highly DE genes $\left(n=286, F D R<0.1,\left|\log _{2}(\mathrm{FC})\right| \geq 1\right)$ enriched across all ages $(12,18$ and $24 \mathrm{hpf})$ and Vitamin $\mathrm{E}$ (VitE) status by over-representation analysis. Terms are separated by (A) Biological Process, (B) Molecular Function and (C) Cellular Component. * indicates significant FDR $<0.25$ with all enrichments shown considered significant. 
Genes $(n=22,796)$ were ranked by their fold-change in expression level between Eand E+ sample groups. Using the ranked genes, Gene Set Enrichment Analysis (GSEA) was carried out using WebGestalt (Figure 4). All GSEA enrichments shown are significant $(F D R<0.25)$. At $12 \mathrm{hpf}, \mathrm{E}-\mathrm{vs} \mathrm{E}+$ embryos have increased expression of genes associated with vitamin $C$ binding, demethylation and demethylase activity, metabolic processes and decreased expression of genes associated with collagen synthesis and protein import (Figure 4A). At $18 \mathrm{hpf}, \mathrm{E}-\mathrm{vs} \mathrm{E}+$ embryos have increased expression of genes associated with vitamin $C$ binding and decreased expression of genes associated with oxidoreductase activity, gene expression regulation, endothelium development and membrane protein transport activity (Figure 4B). At $24 \mathrm{hpf}$, E- vs E+ embryos have increased expression genes associated with neuron ensheathment activity and decreased expression of genes associated with gene transcription regulation (Figure 4C).

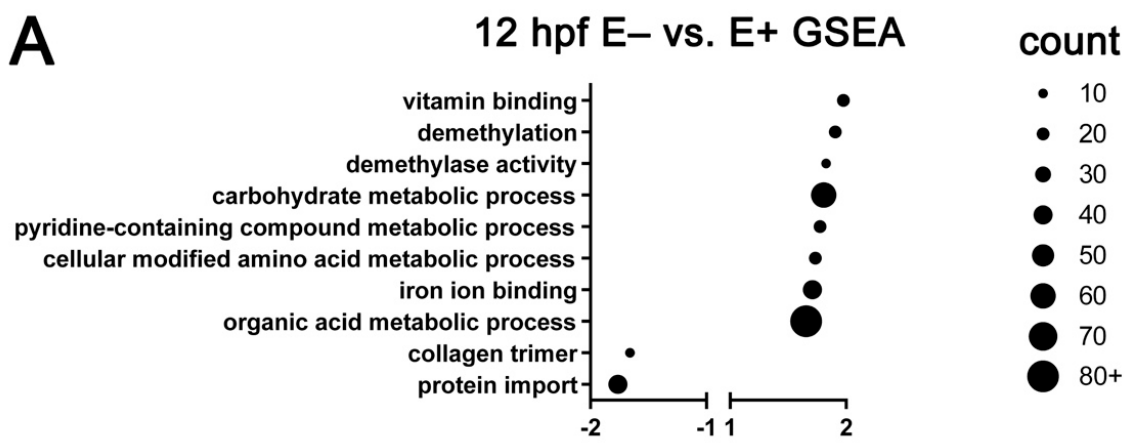

Normalized enrichment score

B

18 hpf E-vs. E+ GSEA

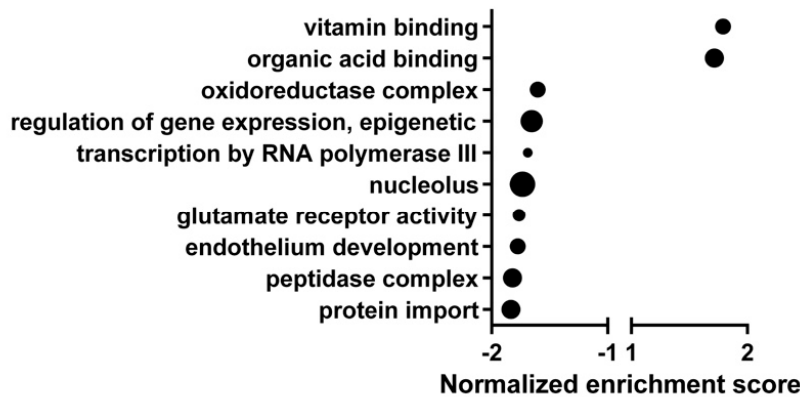

C

24 hpf E-vs. E+ GSEA

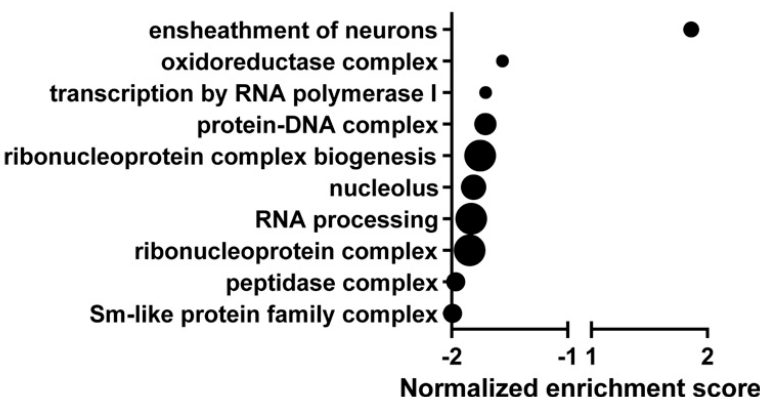

Figure 4. Gene ontology terms enriched by gene set enrichment analysis of all expressed genes. GO annotations associated with all genes $(n=22,796)$ pre-ranked, analyzed by time $(12,18,24 \mathrm{hpf})$ and organized by normalized enrichment score. Top 10 significant $(F D R<0.25) \mathrm{GO}$ terms are separated by expression at (A) $12 \mathrm{hpf}$, (B) $18 \mathrm{hpf}$ and (C) $24 \mathrm{hpf}$. Approximate number of genes found enriched in each term indicated by dot size. Positive enrichment score indicates increased expression in E- relative to E+ embryos, negative enrichment score indicates decreased expression in E- relative to E+ embryos. Normalized enrichment score automatically computed with enrichment and adjusted $p$-value by WebGestalt. 
Metabolomics data, previously acquired [11], were integrated with the gene expression profiles reported herein (both data sets were from $24 \mathrm{hpf}$ E+ and E- embryos) and submitted to MetaboAnalyst. VitE status significantly $\left(F D R=2.39 \times 10^{-28}\right)$ altered the mTOR signaling pathway (Figure 5A), as shown with metabolites (circles) and genes (squares), which were either increased (red) or decreased (green) in E- relative to E+ embryos. This finding was also validated by Western blot analysis of protein extracts obtained from $24 \mathrm{hpf}$ E- and E+ embryos using $\beta$-actin to quantify protein levels and the phosphorylated-tounphosphorylated protein ratio calculated (Figure 5B). Raptor, a key component of mTOR complex 1 (mTORC1) was decreased in E- embryos. The phosphorylated protein (p-) abundance indicates active or inactive state relative to the unmodified protein, depending on the protein. In E- relative to E+ embryos, at $24 \mathrm{hpf}$ p-Rps6 kinase (p-Rps6k) was decreased more than two-fold, p-eukaryotic translation initiation factor 2A ( $\mathrm{p}$-Eif2a) was decreased two-fold, and p-eukaryotic translation initiation factor 4E-binding protein 1 (p-Eif4ebp1) was increased 1.5-fold. These outcomes all support the finding that mTOR signaling was dysregulated at $24 \mathrm{hpf}$ in E- embryos in comparison to E+ embryos.

A

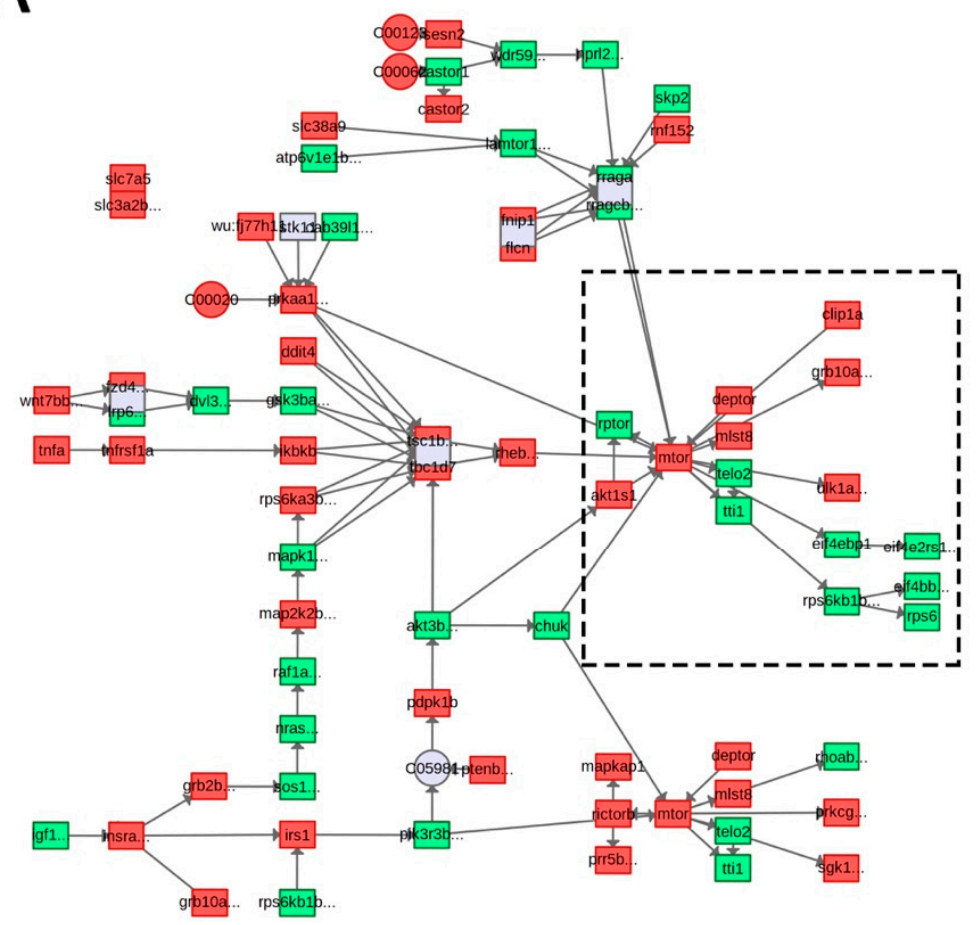

Red means up in EGreen means down in E-

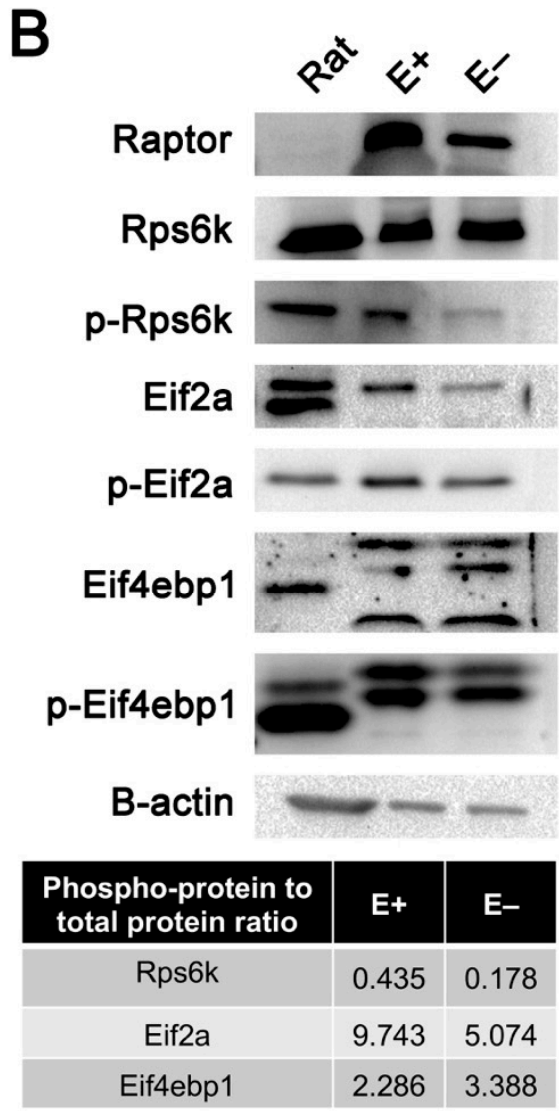

Figure 5. Mechanistic target of rapamycin (mTOR) signaling pathway disrupted in 24 hpf E- embryos. (A) E+ and Eembryos at $24 \mathrm{hpf}$ metabolomic data acquired previously were integrated with gene expression profiles using MetaboAnalyst to generate network profiles. The mTOR signaling pathway was significantly enriched with both metabolites and genes expressed in $24 \mathrm{hpf}$ E- embryos. Red boxes or circles represent increased, while green boxes represent reduced metabolite or gene expression, respectively, in E- relative to E+ embryos. (B) mTOR complex 1 (mTORC1)-associated proteins including Raptor, Rps6k, Eif2a and Eif4ebp1 were evaluated by activity determined by phosphorylation status in pooled protein extracts of rat liver (positive control), E+ and E- embryos ( $n=30$ embryos/pool) at 24 hpf. Phospho-protein (p-) to unphosphorylated protein ratio is calculated for the representative lanes shown.

Over-representation analysis was used for transcription factor (TF) enrichment to determine the extent to which gene expression trends are associated with similar TF regulatory units or promoter regions. DE genes shared the consensus site for TF binding 
YGTCCTTGR motif ( $n=12$ genes, $F D R=0.029)$. Top DE TFs were identified from the dataset (Table 2). The most DE TF, $n r 2 f 1 b$, is expressed in the midbrain hindbrain boundary region and somites of the zebrafish embryo during segmentation [31]. Other highly DE TFs include mafaa, expressed in the neural tube and myotomes during segmentation [32], and zgc:101562, orthologous to human ZCAN10, ZNF398 and ZNF777. Due to VitE's role in prevention of propagation of lipid peroxidation, other genes of interest including ttpa, ttpal, gpx4a, gpx4b and others were evaluated but were not found to be differentially expressed.

Table 2. Top transcription factors differentially expressed in E- embryos across the developmental window measured. Transcription factors (TFs) identified within DEG list annotated for TF family, anatomical region of expression at the measured time point and $\log _{2} \mathrm{FC}$ in $\mathrm{E}-$ embryos relative to $\mathrm{E}+$.

\begin{tabular}{|c|c|c|c|c|c|}
\hline \multirow{2}{*}{ Symbol } & \multirow{2}{*}{ Name } & \multicolumn{3}{|c|}{$\log _{2} \mathrm{FC}$ in $\mathrm{E}-\mathrm{vs} . \mathrm{E}+$} & \multirow{2}{*}{ FDR } \\
\hline & & $12 \mathrm{hpf}$ & $18 \mathrm{hpf}$ & $24 \mathrm{hpf}$ & \\
\hline$n r 2 f 1 b$ & Nuclear receptor subfamily 2 , group $\mathrm{F}$, member $1 \mathrm{~b}$ & -2.21 & 0.17 & 0.12 & 0.007 \\
\hline mafaa & $\begin{array}{c}\text { v-maf avian musculoaponeurotic fibrosarcoma } \\
\text { oncogene homolog Aa }\end{array}$ & -1.83 & -0.22 & 0.13 & 0.008 \\
\hline hsf1 & Heat shock transcription factor 1 & 0.68 & 0.55 & -0.08 & 0.013 \\
\hline$z_{c c}: 101562$ & zgc:101562 & -0.94 & -1.11 & -1.45 & 0.020 \\
\hline tead1b & TEA domain family member $1 b$ & 0.46 & 0.26 & 0.15 & 0.024 \\
\hline$m b d 3 b$ & Methyl-CpG binding domain protein $3 \mathrm{~b}$ & -0.32 & -0.35 & -0.23 & 0.024 \\
\hline tox2 & TOX high mobility group box family member 2 & -0.48 & -0.41 & -0.08 & 0.027 \\
\hline$h m g b 2 b$ & High mobility group box $2 \mathrm{~b}$ & -0.14 & 0.49 & 0.04 & 0.047 \\
\hline bhlhe 40 & Basic helix-loop-helix family, member e40 & 0.86 & 0.17 & 0.12 & 0.061 \\
\hline tbx18 & T-box transcription factor & -0.81 & -0.33 & -0.42 & 0.066 \\
\hline
\end{tabular}

\section{Discussion}

The outcomes of this study show that VitE deficiency disrupts numerous gene expression networks, including energy metabolism, oxidoreductase activity, intra- and intercellular signaling, and developmental transcriptional regulation, during critical developmental windows in zebrafish embryos. We previously identified that VitE deficiency prevents proper neural crest cell migration and impairs midbrain-hindbrain development [12].

E- zebrafish embryos at $24 \mathrm{hpf}$ experience metabolic dysfunction with reduced glycolytic intermediates and increased basal oxygen consumption rates [11]. These metabolic changes are echoed by the gene expression profiles of E- embryos between 12 to $24 \mathrm{hpf}$ reported herein. Similarly, rat embryos between E10.5 and E12.5, developmentally comparable to zebrafish embryos at $24 \mathrm{hpf}[7,8]$, exhibit increased expression levels of genes involved in glycolytic pathways, presumably to increase production of reducing equivalents and precursor molecules via the pentose phosphate pathway. [33]. We found that the greatest changes in gene expression in E- embryos were metabolic processes that generate $\mathrm{NADPH}, \mathrm{ATP}$ and other precursor compounds through glycolysis, the TCA cycle, and oxidative phosphorylation gene expression networks. Tixier et al. showed that glycolytic pathway induction is required to fuel the rapid growth of zebrafish embryos between 0 and $48 \mathrm{hpf}$ [17]. Glycolysis-related gene expression in E- embryos at 12, 18, and $24 \mathrm{hpf}$ is further supported by increased expression of transcription factor tead1b (Table 2, FDR $=0.024$ ). Glycolytic genes are necessary for anabolic growth and key morphogenesis pathways in embryonic development, which we previously reported are significantly altered in Eembryos [12,19]. E- relative to E+ embryos at $36 \mathrm{hpf}$ had similar misexpression of carbohydrate metabolism related genes in embryos in our previous microarray experiments [34]. We reported that these same TCA cycle and glycolytic gene products were altered using a proteomic profile in adult zebrafish fed VitE-deficient diets [35]. Vitamin E-deficient rat livers were analyzed by NMR and were found also to have decreased glucose levels [36]. Thus, VitE deficiency appears to impair production of energy.

Metabolic pathways are also critical for cellular compensation in response to lipid peroxidation (LPO). We reported previously the depletion of long chain polyunsaturated 
fatty acids, specifically docosahexaenoic acid (22:6n-3), in the E- embryos [18] and E- adult zebrafish [37]. Additionally, an LPO biomarker, malondialdehyde (MDA) was increased in E- adult zebrafish [38]. LPO requires detoxification by oxidation of glutathione (GSH). To replenish GSH requires synthesis using the limiting amino acid, cysteine. We have found in E- embryos that choline is depleted, betaine is increased [19] and the methyl donor status [19], along with the thiol status, is disrupted. In addition, oxidized glutathione (GSSG), which requires enzymatic reduction using $\mathrm{NAD}(\mathrm{P}) \mathrm{H}$, is increased [19]. Thus, the E- embryo, over time, is unable to compensate for the increasing LPO.

Zgc:101562 and mafaa, two differentially expressed transcription factors in E- embryos, are associated with gene expression related to glucose regulation and are expressed in mouse neural tissue at E12.5 [28,39,40] and the zebrafish neural tube during the segmentation period (between 10 and $24 \mathrm{hpf}$ [ $[28,38,39]$, respectively. Together, key TFs dysregulated by VitE deficiency, associated with metabolism and localized to early neurologic structures of the vertebrate embryo, highlight VitE's necessary role in maintaining growth pathways and preventing neurodevelopmental defects we reported previously [12]. Importantly, we showed that glucose injections at $24 \mathrm{hpf}$ rescued $~ 70 \%$ of E- embryos [11], providing a clue that earlier intervention may alter transcriptional responses and fully rescue Eanimals through remediation of glycolysis. Importantly, vertebrate neurogenesis formation requires mTOR signaling [41,42] and mTOR is expressed in the zebrafish trunk and brain at $24 \mathrm{hpf}$ [43].

Overall, genes associated with metabolism and mTOR signal integration, used to regenerate the metabolic intermediates described, appear to be the mechanism for the compensatory responses to VitE deficiency. mTOR senses energy and amino acid status signals to stimulate cell survival, growth and proliferation [22]. mTOR is reported also to sense redox status through modulation of glutathione status in the mouse cerebellum [23]. The alteration in mTORC1 at $24 \mathrm{hpf}$ reported herein show that VitE deficiency has a major impact on this key regulator. Additional studies are needed to evaluate the longitudinal changes, along with quantitation of the key mediators, which are likely to accompany the depleted glucose status, oxidized lipids and other cellular stressors.

mTOR contributes to ensheathment in the zebrafish embryo [24] and requires cholesterol for myelination, cytoskeletal support and membrane-specific signaling pathways [44]. We report herein that E- embryo transcripts are enriched for cytoskeleton filament, anchored membrane components and experience metabolic disruption sensed by mTOR. Our data indicate that mTOR signaling is indeed disturbed in E- embryos by $24 \mathrm{hpf}$ with a 3-fold reduction of phosphorylated Rps6k and 2-fold reduction of phosphorylated Eif2a relative to E+ embryos. In addition, expression of genes associated with ensheathment of neurons was positively enriched in E- embryos at $24 \mathrm{hpf}$. Previously, we showed that a VitE deficiency impacts neural crest cell gene expression patterns and somite integrity as early as $12 \mathrm{hpf}$. Myelination and ensheathment pathways immediately follow the migration of sensory axons away from the central nervous system (CNS) towards the periphery [45], a process dependent on neural crest cells [46,47]. Hypothetically, the errors at $12 \mathrm{hpf}$ may precede the effects observed in $24 \mathrm{hpf}$ E- embryos. Sensory neurons are derived from Sox10-expressing neural crest cells [48], which we previously reported to be reduced in number and mis-localized in E- embryos at 12 and $24 \mathrm{hpf}$ [12]. Thus, we suggest that VitE deficiency may disrupt mTOR signaling cascades and subsequent ensheathment pathways that begin during axonal migration from the CNS at $24 \mathrm{hpf}$.

Many other pathways were impacted by VitE deficiency, of note is collagen remodeling. egln3, expressed in the neural plate in $12 \mathrm{hpf}$ zebrafish embryos [32], is a hypoxia inducible factor (HIF) target and regulates the expression of collagen remodeling genes $p 4 h a 1 b$, plod1 $a$ and col1a1b $[49,50]$. VitE radicals produced as a result of lipid peroxidation reactions are chemically reduced by ascorbic acid (Vitamin C (VitC)), thereby depleting this critical antioxidant micronutrient [51]. Zebrafish, like humans, likely do not synthesize VitC and require it in their diet $[52,53]$. VitC was increasingly depleted in E- relative to E+ embryos up to $120 \mathrm{hpf}$ [11]. We observed herein that vitamin binding, annotated primarily with 
VitC-associated gene expression, was positively enriched in E- embryos at 12 and $18 \mathrm{hpf}$, indicating VitC's important early role in development [54-56]. VitC is required for collagen prolyl hydroxylation, catalyzed by the $p 4 h a$ family of genes, including $p 4 h a 1 b$ found in this study [57]. Together, a VitE deficiency and induced VitC deficiency can dramatically alter collagen remodeling pathways in zebrafish embryo vascularization, skin growth and even axonal projections of the brain [58]. Negative enrichment of genes associated with collagen trimer at $12 \mathrm{hpf}$ and endothelium development at $18 \mathrm{hpf}$ in E- embryos further highlights VitE's role in maintaining structural support during embryonic development of the notochord and somites [59].

In addition, there were numerous genes differentially expressed at 12, 18 and $24 \mathrm{hpf}$ in E- embryos that might suggest multiple developmental pathways disturbed, including$n r 2 f 1 b$, a transcription factor decreased in $\mathrm{E}-$ embryos at $12 \mathrm{hpf}\left(\log _{2} \mathrm{FC}=-2.21, F D R=0.007\right)$ that regulates vascularization and hindbrain regionalization in zebrafish [60]; nitr3r.1l, an immune receptor significantly increased in E- embryos at 12 and $18 \mathrm{hpf}\left(\log _{2} \mathrm{FC}=6.14\right.$ and 2.06, respectively) but decreased at $24 \mathrm{hpf}\left(\log _{2} \mathrm{FC}=-2.31\right)$ [61]; and cngb3.2, a cation transmembrane transporter increased in E- embryos at 18 and $24 \mathrm{hpf}\left(\log _{2} \mathrm{FC}=2.94\right.$ and 1.59 , respectively) implicated in the pathology of retinitis pigmentosa [62], a symptom of VitE deficiency in humans [63]. We also compared our data to that of other VitE deficiency models. Unfortunately, comparisons between species including the mouse, rat, and horse, between tissue types, and by age of development are limited. Thus, we found little to no overlap between our dataset and that of others published [64-67]. It is most likely that the zebrafish embryo prior to $24 \mathrm{hpf}$ simply does not share similar gene expression profiles of highly differentiated tissues such as the cerebellum, spinal cord or liver. Myelination pathways, for example, are not highly expressed in early development and thus are not differentially expressed in the E- embryo.

In summary, we show that VitE deficiency as early as $12 \mathrm{hpf}$ disrupts pathways underlying growth and development. This study also points to major metabolic dysfunctions occurring as early as $12 \mathrm{hpf}$. Simultaneously, E- embryos experience LPO disruption to membrane structure and signaling pathways, both of which are known secondary effects due to VitE deficiency. Errors occurring as early as $12 \mathrm{hpf}$ signal catastrophic decline and impairment to neurodevelopment that relies on early signaling capacity for cellular migration, proliferation and overall tissue and organ development. There remains a need to further investigate the origins of VitE deficiency-induced embryonic death as a means of preventing developmental defects and improving prenatal health span.

Supplementary Materials: The following are available online at https:/ / www.mdpi.com/2072-664 3/13/2/468/s1, Figure S1: Multi-dimensional scaling plots of E+ and E- log10CPM clustered at each time point prior to data filtration and normalization.

Author Contributions: B.H., S.A.R., C.K., R.L.T. and M.G.T. contributed to conception or design of the work. All authors contributed to acquisition, analysis or interpretation of data and have drafted or substantively revised the work. All authors have read and agreed to the published version of the manuscript.

Funding: The research reported in this publication was partially supported by the National Institute of Environmental Health Sciences of the National Institutes of Health under Award P30ES030287. The content is solely the responsibility of the authors and does not necessarily represent the official views of the National Institutes of Health.

Institutional Review Board Statement: All experimental protocols and methods were carried out in accordance with the animal use and care protocol (\# 5068) approved by the Institutional Animal Care and Use Committee at Oregon State University.

Informed Consent Statement: Not applicable.

Data Availability Statement: RNASeq data for this study has been deposited in Gene Expression Omnibus with accession number GSE164848 and can be viewed at: https: / / www.ncbi.nlm.nih.gov / geo / query / acc.cgi?acc=GSE164848. 
Acknowledgments: The authors would like to acknowledge Carrie Barton, Chris Sullivan and the Center for Genomic Research and Biocomputing for their outstanding technical assistance. The authors would also like to thank Viviana Perez for sharing the reagents and antibodies used for Western blot analysis. BH is supported by the Marion T. Tsefelas-Linus Pauling Institute Endowed Graduate Fellowship. MGT is supported in part by the Ava Helen Pauling endowment to the Linus Pauling Institute.

Conflicts of Interest: The authors declare no competing financial and/or non-financial interests in relation to the work described.

\section{References}

1. Traber, M.G.; Atkinson, J. Vitamin E, antioxidant and nothing more. Free Radic. Biol. Med. 2007, 43, 4-15. [CrossRef]

2. Zingg, J.M. Vitamin E: Regulatory Role on Signal Transduction. IUBMB Life 2019, 71, 456-478. [CrossRef]

3. Mene-Saffrane, L.; DellaPenna, D. Biosynthesis, regulation and functions of tocochromanols in plants. Plant Physiol. Biochem. 2010, 48, 301-309. [CrossRef]

4. Evans, H.M.; Bishop, K.S. On the Existence of a Hitherto Unrecognized Dietary Factor Essential for Reproduction. Science 1922, 56, 650-651. [CrossRef] [PubMed]

5. Steele, C.E.; Jeffery, E.H.; Diplock, A.T. The effect of vitamin E and synthetic antioxidants on the growth in vitro of explanted rat embryos. J. Reprod. Fertil. 1974, 38, 115-123. [CrossRef] [PubMed]

6. Jishage, K.; Tachibe, T.; Ito, T.; Shibata, N.; Suzuki, S.; Mori, T.; Hani, T.; Arai, H.; Suzuki, H. Vitamin E is essential for mouse placentation but not for embryonic development itself. Biol. Reprod. 2005, 73, 983-987. [CrossRef]

7. Altman, P.L.; Dittmer, D.S. (Eds.) Growth, including reproduction and morphological development; Federation of American Societies for Experimental Biology: Washington, DC, USA, 1962; Volume xiv, p. 608.

8. Kimmel, C.B.; Ballard, W.W.; Kimmel, S.R.; Ullmann, B.; Schilling, T.F. Stages of embryonic development of the zebrafish. Dev. Dyn. 1995, 203, 253-310. [CrossRef] [PubMed]

9. Miller, G.W.; Ulatowski, L.; Labut, E.M.; Lebold, K.M.; Manor, D.; Atkinson, J.; Barton, C.L.; Tanguay, R.L.; Traber, M.G. The alpha-tocopherol transfer protein is essential for vertebrate embryogenesis. PLoS ONE 2012, 7, e47402. [CrossRef]

10. Miller, G.W.; Labut, E.M.; Lebold, K.M.; Floeter, A.; Tanguay, R.L.; Traber, M.G. Zebrafish (Danio rerio) fed vitamin E-deficient diets produce embryos with increased morphologic abnormalities and mortality. J. Nutr. Biochem. 2012, 23, 478-486. [CrossRef]

11. McDougall, M.; Choi, J.; Kim, H.K.; Bobe, G.; Stevens, J.F.; Cadenas, E.; Tanguay, R.; Traber, M.G. Lethal dysregulation of energy metabolism during embryonic vitamin E deficiency. Free Radic. Biol. Med. 2017, 104, 324-332. [CrossRef]

12. Head, B.; La Du, J.; Tanguay, R.L.; Kioussi, C.; Traber, M.G. Vitamin E is necessary for zebrafish nervous system development. Sci. Rep. 2020, 10, 15028. [CrossRef] [PubMed]

13. Santander, N.; Lizama, C.; Parga, M.J.; Quiroz, A.; Perez, D.; Echeverria, G.; Ulloa, L.; Palma, V.; Rigotti, A.; Busso, D. Deficient Vitamin E Uptake During Development Impairs Neural Tube Closure in Mice Lacking Lipoprotein Receptor SR-BI. Sci. Rep.-Uk 2017, 7. [CrossRef] [PubMed]

14. Homanics, G.E.; Maeda, N.; Traber, M.G.; Kayden, H.J.; Dehart, D.B.; Sulik, K.K. Exencephaly and hydrocephaly in mice with targeted modification of the apolipoprotein B (Apob) gene. Teratology 1995, 51, 1-10. [CrossRef] [PubMed]

15. Ulatowski, L.; Parker, R.; Warrier, G.; Sultana, R.; Butterfield, D.A.; Manor, D. Vitamin E is essential for Purkinje neuron integrity. Neuroscience 2014, 260, 120-129. [CrossRef] [PubMed]

16. Yokota, T.; Igarashi, K.; Uchihara, T.; Jishage, K.; Tomita, H.; Inaba, A.; Li, Y.; Arita, M.; Suzuki, H.; Mizusawa, H.; et al. Delayed-onset ataxia in mice lacking alpha -tocopherol transfer protein: Model for neuronal degeneration caused by chronic oxidative stress. Proc. Natl. Acad. Sci. USA 2001, 98, 15185-15190. [CrossRef]

17. Tixier, V.; Bataille, L.; Etard, C.; Jagla, T.; Weger, M.; Daponte, J.P.; Strahle, U.; Dickmeis, T.; Jagla, K. Glycolysis supports embryonic muscle growth by promoting myoblast fusion. Proc. Natl. Acad. Sci. USA 2013, 110, 18982-18987. [CrossRef]

18. McDougall, M.; Choi, J.; Kim, H.K.; Bobe, G.; Stevens, J.F.; Cadenas, E.; Tanguay, R.; Traber, M.G. Lipid quantitation and metabolomics data from vitamin E-deficient and -sufficient zebrafish embryos from 0 to 120 hours-post-fertilization. Data Brief. 2017, 11, 432-441. [CrossRef]

19. Zhang, J.; Head, B.; Leonard, S.W.; Choi, J.; Tanguay, R.L.; Traber, M.G. Vitamin E deficiency dysregulates thiols, amino acids and related molecules during zebrafish embryogenesis. Redox. Biol. 2020, 38, 101784. [CrossRef]

20. Lee, M.S.; Bonner, J.R.; Bernard, D.J.; Sanchez, E.L.; Sause, E.T.; Prentice, R.R.; Burgess, S.M.; Brody, L.C. Disruption of the folate pathway in zebrafish causes developmental defects. BMC Dev. Biol. 2012, 12, 12. [CrossRef]

21. White, R.J.; Collins, J.E.; Sealy, I.M.; Wali, N.; Dooley, C.M.; Digby, Z.; Stemple, D.L.; Murphy, D.N.; Billis, K.; Hourlier, T.; et al. A high-resolution mRNA expression time course of embryonic development in zebrafish. Elife 2017, 6. [CrossRef]

22. Shimobayashi, M.; Hall, M.N. Multiple amino acid sensing inputs to mTORC1. Cell Res. 2016, 26, 7-20. [CrossRef]

23. Garza-Lombo, C.; Petrosyan, P.; Tapia-Rodriguez, M.; Valdovinos-Flores, C.; Gonsebatt, M.E. Systemic L-buthionine-S-Rsulfoximine administration modulates glutathione homeostasis via NGF/TrkA and mTOR signaling in the cerebellum. Neurochem. Int. 2018, 121, 8-18. [CrossRef] [PubMed] 
24. Kearns, C.A.; Ravanelli, A.M.; Cooper, K.; Appel, B. Fbxw7 Limits Myelination by Inhibiting mTOR Signaling. J. Neurosci. 2015, 35, 14861-14871. [CrossRef] [PubMed]

25. Milanese, C.; Bombardieri, C.R.; Sepe, S.; Barnhoorn, S.; Payan-Gomez, C.; Caruso, D.; Audano, M.; Pedretti, S.; Vermeij, W.P.; Brandt, R.M.C.; et al. DNA damage and transcription stress cause ATP-mediated redesign of metabolism and potentiation of anti-oxidant buffering. Nat. Commun. 2019, 10, 4887. [CrossRef] [PubMed]

26. Podda, M.; Weber, C.; Traber, M.G.; Packer, L. Simultaneous determination of tissue tocopherols, tocotrienols, ubiquinols, and ubiquinones. J. Lipid Res. 1996, 37, 893-901. [CrossRef]

27. Liao, Y.; Wang, J.; Jaehnig, E.J.; Shi, Z.; Zhang, B. WebGestalt 2019: Gene set analysis toolkit with revamped UIs and APIs. Nucleic. Acids Res. 2019, 47, W199-W205. [CrossRef] [PubMed]

28. Ruzicka, L.; Howe, D.G.; Ramachandran, S.; Toro, S.; Van Slyke, C.E.; Bradford, Y.M.; Eagle, A.; Fashena, D.; Frazer, K.; Kalita, P.; et al. The Zebrafish Information Network: New support for non-coding genes, richer Gene Ontology annotations and the Alliance of Genome Resources. Nucleic. Acids Res. 2019, 47, D867-D873. [CrossRef] [PubMed]

29. Pang, Z.; Chong, J.; Li, S.; Xia, J. MetaboAnalystR 3.0: Toward an Optimized Workflow for Global Metabolomics. Metabolites 2020, 10, 186. [CrossRef] [PubMed]

30. Scheldeman, C.; Mills, J.D.; Siekierska, A.; Serra, I.; Copmans, D.; Iyer, A.M.; Whalley, B.J.; Maes, J.; Jansen, A.C.; Lagae, L.; et al. mTOR-related neuropathology in mutant tsc2 zebrafish: Phenotypic, transcriptomic and pharmacological analysis. Neurobiol. Dis. 2017, 108, 225-237. [CrossRef]

31. Love, C.E.; Prince, V.E. Expression and retinoic acid regulation of the zebrafish nr2f orphan nuclear receptor genes. Dev. Dyn. 2012, 241, 1603-1615. [CrossRef]

32. Thisse, C.; Thisse, B. High-resolution in situ hybridization to whole-mount zebrafish embryos. Nat. Protoc. 2008, 3, 59-69. [CrossRef] [PubMed]

33. Tanimura, T.; Shepard, T.H. Glucose metabolism by rat embryos in vitro. Proc. Soc. Exp. Biol. Med. 1970, 135, 51-54. [CrossRef] [PubMed]

34. Miller, G.W.; Truong, L.; Barton, C.L.; Labut, E.M.; Lebold, K.M.; Traber, M.G.; Tanguay, R.L. The influences of parental diet and vitamin E intake on the embryonic zebrafish transcriptome. Comp. Biochem. Physiol. Part D Genomics. Proteomics. 2014, 10, 22-29. [CrossRef] [PubMed]

35. Motorykin, I.; Traber, M.G.; Tanguay, R.L.; Maier, C.S. Proteome-driven elucidation of adaptive responses to combined vitamin E and C deficiency in zebrafish. J. Proteome. Res. 2014, 13, 1647-1656. [CrossRef] [PubMed]

36. Moazzami, A.A.; Andersson, R.; Kamal-Eldin, A. Changes in the metabolic profile of rat liver after alpha-tocopherol deficiency as revealed by metabolomics analysis. NMR Biomed. 2011, 24, 499-505. [CrossRef] [PubMed]

37. Lebold, K.M.; Jump, D.B.; Miller, G.W.; Wright, C.L.; Labut, E.M.; Barton, C.L.; Tanguay, R.L.; Traber, M.G. Vitamin E deficiency decreases long-chain PUFA in zebrafish (Danio rerio). J. Nutr. 2011, 141, 2113-2118. [CrossRef]

38. Lebold, K.M.; Lohr, C.V.; Barton, C.L.; Miller, G.W.; Labut, E.M.; Tanguay, R.L.; Traber, M.G. Chronic vitamin E deficiency promotes vitamin $\mathrm{C}$ deficiency in zebrafish leading to degenerative myopathy and impaired swimming behavior. Comp. Biochem. Physiol. C Toxicol. Pharmacol. 2013, 157, 382-389. [CrossRef]

39. Zhang, C.; Skamagki, M.; Liu, Z.; Ananthanarayanan, A.; Zhao, R.; Li, H.; Kim, K. Biological Significance of the Suppression of Oxidative Phosphorylation in Induced Pluripotent Stem Cells. Cell Rep 2017, 21, 2058-2065. [CrossRef]

40. Kraus, P.; V, S.; Yu, H.B.; Xing, X.; Lim, S.L.; Adler, T.; Pimentel, J.A.; Becker, L.; Bohla, A.; Garrett, L.; et al. Pleiotropic functions for transcription factor zscan10. PLoS ONE 2014, 9, e104568. [CrossRef]

41. Fishwick, K.J.; Li, R.A.; Halley, P.; Deng, P.; Storey, K.G. Initiation of neuronal differentiation requires PI3-kinase/TOR signalling in the vertebrate neural tube. Dev. Biol. 2010, 338, 215-225. [CrossRef]

42. Kadoya, M.; Sasai, N. Negative Regulation of mTOR Signaling Restricts Cell Proliferation in the Floor Plate. Front Neurosci. 2019, 13, 1022. [CrossRef] [PubMed]

43. Makky, K.; Tekiela, J.; Mayer, A.N. Target of rapamycin (TOR) signaling controls epithelial morphogenesis in the vertebrate intestine. Dev. Biol. 2007, 303, 501-513. [CrossRef] [PubMed]

44. Mathews, E.S.; Appel, B. Cholesterol Biosynthesis Supports Myelin Gene Expression and Axon Ensheathment through Modulation of P13K/Akt/mTor Signaling. J. Neurosci. 2016, 36, 7628-7639. [CrossRef] [PubMed]

45. Blauth, K.; Banerjee, S.; Bhat, M.A. Axonal ensheathment and intercellular barrier formation in Drosophila. Int. Rev. Cell Mol. Biol. 2010, 283, 93-128. [CrossRef]

46. Woodhoo, A.; Sommer, L. Development of the Schwann cell lineage: From the neural crest to the myelinated nerve. Glia 2008, 56, 1481-1490. [CrossRef]

47. Barraud, P.; Seferiadis, A.A.; Tyson, L.D.; Zwart, M.F.; Szabo-Rogers, H.L.; Ruhrberg, C.; Liu, K.J.; Baker, C.V. Neural crest origin of olfactory ensheathing glia. Proc. Natl. Acad. Sci. USA 2010, 107, 21040-21045. [CrossRef]

48. McGraw, H.F.; Snelson, C.D.; Prendergast, A.; Suli, A.; Raible, D.W. Postembryonic neuronal addition in zebrafish dorsal root ganglia is regulated by Notch signaling. Neural. Dev. 2012, 7, 23. [CrossRef]

49. Marchi, D.; Santhakumar, K.; Markham, E.; Li, N.; Storbeck, K.H.; Krone, N.; Cunliffe, V.T.; van Eeden, F.J.M. Bidirectional crosstalk between Hypoxia-Inducible Factor and glucocorticoid signalling in zebrafish larvae. PLoS Genet. 2020, 16, e1008757. [CrossRef] 
50. Pescador, N.; Cuevas, Y.; Naranjo, S.; Alcaide, M.; Villar, D.; Landazuri, M.O.; Del Peso, L. Identification of a functional hypoxiaresponsive element that regulates the expression of the egl nine homologue 3 (egln3/phd3) gene. Biochem. J. 2005, 390, 189-197. [CrossRef]

51. Packer, J.E.; Slater, T.F.; Willson, R.L. Direct observation of a free radical interaction between vitamin E and vitamin C. Nature 1979, 278, 737-738. [CrossRef]

52. Drouin, G.; Godin, J.-R.; Pagé, B. The genetics of vitamin C loss in vertebrates. Curr. Genom. 2011, 12, 371-378. [CrossRef] [PubMed]

53. Nishikimi, M.; Yagi, K. Molecular basis for the deficiency in humans of gulonolactone oxidase, a key enzyme for ascorbic acid biosynthesis. Am. J. Clin. Nutr. 1991, 54, 1203S-1208S. [CrossRef] [PubMed]

54. Hasselholt, S.; Tveden-Nyborg, P.; Lykkesfeldt, J. Distribution of vitamin C is tissue specific with early saturation of the brain and adrenal glands following differential oral dose regimens in guinea pigs. Br. J. Nutr. 2015, 113, 1539-1549. [CrossRef] [PubMed]

55. Tveden-Nyborg, P.; Vogt, L.; Schjoldager, J.G.; Jeannet, N.; Hasselholt, S.; Paidi, M.D.; Christen, S.; Lykkesfeldt, J. Maternal vitamin $C$ deficiency during pregnancy persistently impairs hippocampal neurogenesis in offspring of guinea pigs. PLoS ONE 2012, 7, e48488. [CrossRef]

56. Meredith, M.E.; Harrison, F.E.; May, J.M. Differential regulation of the ascorbic acid transporter SVCT2 during development and in response to ascorbic acid depletion. Biochem. Biophys Res. Commun. 2011, 414, 737-742. [CrossRef]

57. D'Aniello, C.; Cermola, F.; Palamidessi, A.; Wanderlingh, L.G.; Gagliardi, M.; Migliaccio, A.; Varrone, F.; Casalino, L.; Matarazzo, M.R.; De Cesare, D.; et al. Collagen Prolyl Hydroxylation-Dependent Metabolic Perturbation Governs Epigenetic Remodeling and Mesenchymal Transition in Pluripotent and Cancer Cells. Cancer Res. 2019, 79, 3235-3250. [CrossRef]

58. Bretaud, S.; Nauroy, P.; Malbouyres, M.; Ruggiero, F. Fishing for collagen function: About development, regeneration and disease. Sem. Cell Dev. Biol. 2019, 89, 100-108. [CrossRef]

59. Henry, C.A.; Crawford, B.D.; Yan, Y.L.; Postlethwait, J.; Cooper, M.S.; Hille, M.B. Roles for zebrafish focal adhesion kinase in notochord and somite morphogenesis. Dev. Biol. 2001, 240, 474-487. [CrossRef]

60. Li, R.F.; Wu, T.Y.; Mou, Y.Z.; Wang, Y.S.; Chen, C.L.; Wu, C.Y. Nr2f1b control venous specification and angiogenic patterning during zebrafish vascular development. J. Biomed. Sci. 2015, 22, 104. [CrossRef]

61. Meyer, D.N.; Baker, B.B.; Baker, T.R. Ancestral TCDD Exposure Induces Multigenerational Histologic and Transcriptomic Alterations in Gonads of Male Zebrafish. Toxicol. Sci. 2018, 164, 603-612. [CrossRef]

62. Iribarne, M.; Masai, I. Neurotoxicity of cGMP in the vertebrate retina: From the initial research on rd mutant mice to zebrafish genetic approaches. J. Neurogenet 2017, 31, 88-101. [CrossRef] [PubMed]

63. Iwasa, K.; Shima, K.; Komai, K.; Nishida, Y.; Yokota, T.; Yamada, M. Retinitis pigmentosa and macular degeneration in a patient with ataxia with isolated vitamin E deficiency with a novel c.717 del C mutation in the TTPA gene. J. Neurol. Sci. 2014, 345, 228-230. [CrossRef] [PubMed]

64. Finno, C.J.; Bordbari, M.H.; Gianino, G.; Ming-Whitfield, B.; Burns, E.; Merkel, J.; Britton, M.; Durbin-Johnson, B.; Sloma, E.A.; McMackin, M.; et al. An innate immune response and altered nuclear receptor activation defines the spinal cord transcriptome during alpha-tocopherol deficiency in Ttpa-null mice. Free Radic. Biol. Med. 2018, 120, 289-302. [CrossRef] [PubMed]

65. Finno, C.J.; Peterson, J.; Kang, M.; Park, S.; Bordbari, M.H.; Durbin-Johnson, B.; Settles, M.; Perez-Flores, M.C.; Lee, J.H.; Yamoah, E.N. Single-Cell RNA-seq Reveals Profound Alterations in Mechanosensitive Dorsal Root Ganglion Neurons with Vitamin E Deficiency. iScience 2019, 21, 720-735. [CrossRef]

66. Fischer, A.; Pallauf, J.; Gohil, K.; Weber, S.U.; Packer, L.; Rimbach, G. Effect of selenium and vitamin E deficiency on differential gene expression in rat liver. Biochem. Biophys Res. Commun. 2001, 285, 470-475. [CrossRef]

67. Gohil, K.; Schock, B.C.; Chakraborty, A.A.; Terasawa, Y.; Raber, J.; Farese, R.V., Jr.; Packer, L.; Cross, C.E.; Traber, M.G. Gene expression profile of oxidant stress and neurodegeneration in transgenic mice deficient in alpha-tocopherol transfer protein. Free Radic. Biol. Med. 2003, 35, 1343-1354. [CrossRef] 